\title{
The Long-Term Prognostic Significance of 6-Minute Walk Test Distance in Patients with Chronic Heart Failure
}

\author{
Lee Ingle, ${ }^{1}$ John G. Cleland, ${ }^{2}$ and Andrew L. Clark ${ }^{3}$ \\ ${ }^{1}$ Department of Sport, Health \& Exercise Science, University of Hull, 104 Don Building, Cottingham Road, \\ Kingston upon Hull, HU7 6RX, UK \\ ${ }^{2}$ National Heart \& Lung Institute, Royal Brompton \& Harefield Hospitals, Imperial College, London, UK \\ ${ }^{3}$ Department of Cardiology, Castle Hill Hospital, Kingston upon Hull, HU16 5JQ, UK
}

Correspondence should be addressed to Lee Ingle; l.ingle@hull.ac.uk

Received 4 November 2013; Accepted 26 February 2014; Published 27 March 2014

Academic Editor: Michael Gotzmann

Copyright (C) 2014 Lee Ingle et al. This is an open access article distributed under the Creative Commons Attribution License, which permits unrestricted use, distribution, and reproduction in any medium, provided the original work is properly cited.

\begin{abstract}
Background. The 6-minute walk test (6-MWT) is used to assess patients with chronic heart failure (CHF). The prognostic significance of the 6-MWT distance during long-term followup (>5 years) is unclear. Methods. 1,667 patients (median [inter-quartile range, IQR]) (age 72 [65-77]; 75\% males) with heart failure due to left ventricular systolic impairment undertook a 6-MWT as part of their baseline assessment and were followed up for 5 years. Results. At 5 years' followup, those patients who died $(n=959)$ were older at baseline and had a higher log NT pro-BNP than those who survived to 5 years $(n=708)$. 6-MWT distance was lower in those who died [163 (153) m versus $269(160) \mathrm{m} ; P<0.0001]$. Median 6-MWT distance was $300(150-376) \mathrm{m}$, and quartile ranges were < $46 \mathrm{~m}, 46-240 \mathrm{~m}, 241-360 \mathrm{~m}$, and >360 m. 6-MWT distance was a predictor of all-cause mortality (HR 0.97; 95\% CI 0.96-0.97; Chi-square $=184.1 ; P<0.0001$ ). Independent predictors of all-cause mortality were decreasing 6-MWT distance, increasing age, increasing NYHA classification, increasing log NT pro-BNP, decreasing diastolic blood pressure, decreasing sodium, and increasing urea. Conclusion. The 6-MWT is an important independent predictor of all-cause mortality following long-term followup in patients with CHF.
\end{abstract}

\section{Introduction}

Functional capacity is strongly related to survival in patients with chronic heart failure (CHF) [1]. Although cardiopulmonary exercise testing (CPET) with metabolic gas exchange measurements is perhaps the "gold standard" method for assessing exercise capacity, it is not widely available, and so more simple tests are commonly used [2]. The 6-minute walk test (6-MWT) is reproducible and sensitive to changes in quality of life [3-5]. It is a self-paced, submaximal test, and exercise intensity mimics activities of daily living in patients with mild-to-moderate heart failure [6-9]. Thus, the 6-MWT may suit patients with CHF who may experience symptoms such as breathlessness below their peak exercise capacity.

We have previously reported that decreasing 6-MWT distance was an independent predictor of increasing mortality in patients with left ventricular systolic dysfunction but that it was a less potent single predictor than $\mathrm{N}$-terminal probrain natriuretic peptide (NT pro-BNP) [10]. Others have shown that the 6-MWT distance is a less powerful predictor of outcome than some variables, such as $\mathrm{VE} / \mathrm{VCO}_{2}$ slope and peak oxygen uptake derived from CPET [11].

The aim of the present study was to assess the long-term ( $>5$ years) prognostic significance of the 6-MWT distance in a large sample of patients with CHF.

\section{Methods}

The Hull and East Riding Ethics Committee approved the study, and all patients provided informed consent for participation. Clinical information obtained included past medical history and drug and smoking history. Clinical examination included assessment of body mass index (BMI), heart rate, rhythm, and blood pressure (BP). Heart failure was defined as current symptoms of heart failure, or a history of symptoms controlled by ongoing therapy, in the presence of reduced left ventricular (LV) systolic function on echocardiography 
and in the absence of any other cause for symptoms [12, 13]. $2 \mathrm{D}$ echocardiography was carried out by one of three trained operators. LV function was assessed by estimation on a scale of normal, mild, mild-to-moderate, moderate, moderate-tosevere, and severe impairment. LV ejection fraction (LVEF) was calculated using Simpson's formula, where possible, from measurements of end-diastolic and end-systolic volumes on apical 2D views, following the guidelines of Schiller et al. [14] and LVSD was diagnosed if LVEF was $<45 \%$.

The 6-MWT was conducted following a standardised protocol $[9,10]$. A $15 \mathrm{~m}$ flat, obstacle-free corridor, with chairs placed at either end, was used. Patients were instructed to walk as far as possible, turning $180^{\circ}$ every $15 \mathrm{~m}$ in the allotted time of $6 \mathrm{~min}$. Patients were able to rest, if needed, and the time remaining was called every second minute [15]. Patients were excluded if they were unable to walk without assistance from another person (not including mobility aids), or if they were unable to exercise because of noncardiac limitations. Patients walked unaccompanied so as not to influence walking speed. After $6 \mathrm{~min}$, patients were instructed to stop and the total distance covered was measured to the nearest metre. Standardised verbal encouragement was given to patients after $2 \mathrm{~min}$ and $4 \mathrm{~min}$. If a patient could not undertake the 6-MWT, a distance of $0 \mathrm{~m}$ was recorded.

2.1. Statistical Analysis. Continuous variables are presented as median with interquartile range (IQR) or standard deviation (SD) and categorical data as percentages. Continuous variables were assessed for normality by the Kolmogorov-Smirnov test. NT pro-BNP was normalised by log-transformation for analysis. Differences between those who survived to five years and those who did not were determined by the independent samples $t$-test or Pearson's Chi-square test. No survivor was followed up for less than 5 years. We used receiver operating characteristic (ROC) curves to assess the predictive power of variables and report the area under the curve (AUC) with 95\% confidence intervals (CI), sensitivity, specificity, and optimal cut-points. To define the optimal cut-point, we used the point closest to the upper left corner of the ROC curve, often known as the $(0,1)$ criterion.

We used Kaplan-Meier curves to display mortality data using the guidance of Pocock et al. [16]. For illustration, 6MWT distance data were divided into quartiles $(\leq 45 \mathrm{~m}, 46-$ $240 \mathrm{~m}, 241-360 \mathrm{~m}$, and $>360 \mathrm{~m}$ ). Cox regression models (univariable and multivariable) were used to develop predictor models using all baseline variables. We used multivariable Cox proportional hazards model using the backward likelihood ratio method ( $P$ value for entry was $<0.05$; $P$ value for removal was $>0.1$ ) to identify independent predictors of all-cause mortality from candidate predictor variables. The assumption of proportionality was tested for each variable using the method of Grambsch and Therneau [17].

To minimise the risk of "overfitting," we were guided by Peduzzi and colleagues $[18,19]$ who suggested an events per variable ratio of $10: 1$. To determine the robustness of our model(s), we performed bootstrapping based on 1,000 stratified samples. We checked for colinearity by calculating Pearson correlation coefficients. We used a cut-off value of
0.3 to identify colinearity. SPSS version 19.0 (IBM, New York, USA) was used to analyse the data. An arbitrary level of 5\% statistical significance was used throughout (two-tailed). We followed the guidance of Perneger [20] and did not adjust for multiple testing in order to avoid the inflation of type I error. The primary outcome measure was all-cause mortality.

\section{Results}

1,667 patients (median (interquartile range, IQR)) (age 72 (65-77); 75\% males) with heart failure due to left ventricular systolic impairment were included in the study. At 5-year followup, those patients who died $(n=959)$ were, at baseline, older and had a lower BMI, higher NYHA class, lower LVEF, higher creatinine, higher log NT pro-BNP, lower haemoglobin, and higher urea levels than those who survived to 5 years $(n=708$; Table 1$)$. 6 -MWT distance was lower in those who died (163 (153) m versus 269 (160) m; $P<$ $0.0001)$. Median 6-MWT distance was 300 (150-376) $\mathrm{m}$, and quartile ranges for 6-MWT distance were $<46 \mathrm{~m}, 46-240 \mathrm{~m}$, 241-360 m, and $>360 \mathrm{~m}$. Table 2 shows clinical characteristics divided by quartiles of 6-MWT distance. There were significant between-group differences for age, BMI, LVEF, resting $\mathrm{HR}$, resting systolic/diastolic $\mathrm{BP}, \mathrm{QRS}$ duration, haemoglobin, $\log$ NT pro-BNP, urea, and creatinine (all $P<0.05$ ).

Thirteen variables were significantly associated with allcause mortality in univariable Cox analysis (Table 3). After bootstrapping, only 6 variables (6-MWT, age, NT proBNP, NYHA class, diastolic BP, and haemoglobin) remained statistically significant (Table 4 ). All variables in Table 1 were included in a final multivariable Cox model, and six were independent predictors of all-cause mortality, decreasing 6MWT distance, increasing age, increasing NYHA classification, increasing NT pro-BNP, decreasing diastolic blood pressure, decreasing sodium, and increasing urea (Table 5). ROC curve analysis of 6-MWT distance and all-cause mortality at 5 years is shown in Figure 1 (AUC $=0.67 ; P<0.0001 ; 95 \%$ $\mathrm{CI}=0.64-0.70$; the optimal cut-point for 6-MWT distance was $350 \mathrm{~m}$ with sensitivity 0.81 and specificity 0.57 ). Figure 2 shows a Kaplan-Meier survival curve for the patients divided by quartiles of 6-MWT distance $(<46 \mathrm{~m}$ : event free survival 24\%; 46-240 m: event free survival 29\%; 241-360 m: event free survival $45 \%$; $>360 \mathrm{~m}$ : event free survival $70 \%$ ).

\section{Discussion}

We have shown that the 6-MWT is an independent predictor of all-cause mortality during long-term (5 year) followup in patients with CHF. To our knowledge, this is the largest study that has focused on the prognostic value of 6-MWT distance during extended followup. We have previously shown that 6MWT distance is an independent predictor of risk following medium-term followup (median 36.6 (28-45) months). In 1,592 patients, 212 died representing a crude death rate of $13.3 \%$. Five independent predictors of all-cause mortality were identified including decreasing 6-MWT distance [10].

Other large-scale studies including the SENIORS trial [21] ( $n=2,128$ patients, $\geq 70$ years with $\mathrm{LVEF} \leq 35 \%$ or recent hospital admission) have also shown that 6-MWT distance 
TABLE 1: Baseline characteristics of patients [mean (SD)] divided by survival to $>5$ years.

\begin{tabular}{|c|c|c|c|}
\hline Variables & Dead $(n=959)$ & Alive $(n=708)$ & $P$ value \\
\hline Age (years) & $74.1(8.9)$ & $67.9(10.6)$ & $<0.0001$ \\
\hline Males (\%) & 73 & 75 & 0.184 \\
\hline $\mathrm{BMI}\left(\mathrm{kg} \cdot \mathrm{m}^{-2}\right)$ & $27.7(5.7)$ & $28.9(5.6)$ & $<0.0001$ \\
\hline \multicolumn{4}{|l|}{ NYHA class } \\
\hline I/II & 36 & 64 & $<0.0001$ \\
\hline III/IV & 58 & 42 & \\
\hline LVEF (\%) & $33(10)$ & $36(9)$ & $<0.0001$ \\
\hline $\mathrm{FEV}_{1} / \mathrm{FVC}(\%)$ & $66(16)$ & $70(16)$ & $<0.0001$ \\
\hline Resting HR (beats. $\min ^{-1}$ ) & $76(18)$ & $74(20)$ & 0.165 \\
\hline Resting systolic BP (mmHg) & $132(26)$ & $133(24)$ & 0.158 \\
\hline Resting diastolic $\mathrm{BP}(\mathrm{mmHg})$ & $74(14)$ & $78(14)$ & $<0.0001$ \\
\hline QRS duration (ms) & $121(32)$ & $112(29)$ & $<0.0001$ \\
\hline Haemoglobin $\left(\mathrm{g} \cdot \mathrm{dL}^{-1}\right)$ & $13.0(1.7)$ & $13.9(1.5)$ & $<0.0001$ \\
\hline Log NT pro-BNP* & $7.7(1.2)$ & $6.7(1.3)$ & $<0.0001$ \\
\hline Sodium $\left(\mathrm{mmol} \cdot \mathrm{L}^{-1}\right)$ & $139(4)$ & $139(3)$ & 0.652 \\
\hline Potassium $\left(\mathrm{mmol} \cdot \mathrm{L}^{-1}\right)$ & $4.4(0.5)$ & $4.4(0.5)$ & 0.777 \\
\hline Urea $\left(\mathrm{mmol} \cdot \mathrm{L}^{-1}\right)$ & $9.3(4.7)$ & $7.1(3.6)$ & $<0.0001$ \\
\hline Creatinine $\left(\mathrm{u} \cdot \mathrm{moL}^{-1}\right)$ & $130(51)$ & $110(55)$ & $<0.0001$ \\
\hline Diuretic (\%) & 83 & 84 & 0.760 \\
\hline ACE-inhibitor (\%) & 78 & 77 & 0.348 \\
\hline Beta-blocker (\%) & 73 & 69 & 0.322 \\
\hline Spironolactone (\%) & 22 & 20 & 0.202 \\
\hline 6-MWT (m) & $163(153)$ & $269(160)$ & $<0.0001$ \\
\hline
\end{tabular}

NYHA: New York Heart Association; BMI: body mass index; LVI: left ventricular impairment; LVEF*: left ventricular ejection fraction available in $67 \%$ of patients; 6-MWT: 6-min walk test; BP: blood pressure; $\log$ NT pro-BNP $\left(\mathrm{pg} \cdot \mathrm{mL}^{-1}\right)^{*}$ available in $92 \%$ of patients.

TABLE 2: Clinical characteristics separated by quartiles of 6-MWT distance in patients with CHF (mean \pm SD).

\begin{tabular}{|c|c|c|c|c|c|}
\hline Variables & $\leq 45 \mathrm{~m}$ & $46-240 \mathrm{~m}$ & $241-360 \mathrm{~m}$ & $>360 \mathrm{~m}$ & $P$ value \\
\hline Age (years) & $72.4(10.6)$ & $72.9(9.6)$ & $71.3(8.8)$ & $64.9(10.6)$ & $<0.0001$ \\
\hline $\mathrm{BMI}\left(\mathrm{kg} \cdot \mathrm{m}^{-2}\right)$ & $27.5(4.5)$ & $27.7(5.2)$ & $28.5(5.8)$ & $28.9(6.8)$ & 0.002 \\
\hline $\operatorname{LVEF}(\%)$ & $32.0(10.0)$ & $35.1(10.7)$ & $34.6(9.2)$ & $36.2(9.3)$ & $<0.0001$ \\
\hline $\mathrm{FEV}_{1} / \mathrm{FVC}(\%)$ & $66.4(17.7)$ & $67.5(15.0)$ & $67.3(16.5)$ & $68.8(16.4)$ & 0.257 \\
\hline Resting HR (beats. $\min ^{-1}$ ) & $80(36)$ & $75(17)$ & $73(17)$ & $72(17)$ & $<0.0001$ \\
\hline Resting systolic BP (mmHg) & $129(29)$ & $134(25)$ & $136(23)$ & $135(23)$ & $<0.0001$ \\
\hline Resting diastolic $\mathrm{BP}(\mathrm{mmHg})$ & $74(14)$ & $77(15)$ & $77(14)$ & $80(14)$ & $<0.0001$ \\
\hline QRS duration (ms) & $117(31)$ & $119(33)$ & $120(32)$ & $114(30)$ & 0.045 \\
\hline Haemoglobin $\left(\mathrm{g} \cdot \mathrm{dL}^{-1}\right)$ & $13.0(1.9)$ & $13.2(1.7)$ & $13.6(1.5)$ & $14.1(1.4)$ & $<0.0001$ \\
\hline Log NT pro-BNP & $7.5(1.4)$ & $7.3(1.4)$ & $7.0(1.2)$ & $6.5(1.3)$ & $<0.0001$ \\
\hline Sodium $\left(\mathrm{mmol} \cdot \mathrm{L}^{-1}\right)$ & $138(3.9)$ & $139(3.8)$ & $139(3.3)$ & $139(3.0)$ & 0.241 \\
\hline Potassium $\left(\mathrm{mmol} \cdot \mathrm{L}^{-1}\right)$ & $4.4(0.6)$ & $4.4(0.5)$ & $4.4(0.5)$ & $4.4(0.5)$ & 0.382 \\
\hline Urea $\left(\mathrm{mmol} \cdot \mathrm{L}^{-1}\right)$ & $9.2(5.0)$ & $8.5(4.7)$ & $7.9(3.9)$ & $6.7(3.8)$ & $<0.0001$ \\
\hline Creatinine $\left(\mathrm{u} \cdot \mathrm{moL}^{-1}\right)$ & $125(52)$ & $121(49)$ & $116(44)$ & $107(65)$ & $<0.0001$ \\
\hline
\end{tabular}

is an independent predictor of mortality over a modest time period (mean followup: 21 months) [21]. Another study [22] (mean followup 34 months) has also confirmed the prognostic value of 6-MWT distance for predicting cardiac-related death in patients with mild-to-moderate CHF. Long-term studies have been reported in patients with stable coronary heart disease, including the Heart and Soul Study [23] which followed up patients for a median of 8.0 (4.2-9.0) years and showed that 6-MWT distance predicted cardiovascular events and provided similar prognostic value to treadmill exercise capacity. A limitation of the study was a small sample size $(n=556)$ and a limited number of events (184 deaths).

A number of studies have shown that 6-MWT distance is a less powerful predictor of outcome in patients with $\mathrm{CHF}$ than variables derived from CPET such as $\mathrm{VE} / \mathrm{VCO}_{2}$ slope and peak oxygen uptake [24]. Opasich and colleagues [25] 
TABLE 3: Unadjusted univariable predictors of all-cause mortality in patients with CHF (in order of Chi-square value).

\begin{tabular}{|c|c|c|c|c|c|}
\hline \multirow{2}{*}{ Variables } & \multirow{2}{*}{$P$ value } & \multirow{2}{*}{ HR } & \multicolumn{2}{|c|}{$95 \% \mathrm{CI}$} & \multirow{2}{*}{ Chi-square } \\
\hline & & & Lower & Upper & \\
\hline Log NT pro-BNP & $<0.0001$ & 1.63 & 1.53 & 1.74 & 230.8 \\
\hline 6-MWT $(\mathrm{m})^{*}$ & $<0.0001$ & 0.968 & 0.964 & 0.973 & 184.1 \\
\hline Age (years) & $<0.0001$ & 1.05 & 1.04 & 1.06 & 137.2 \\
\hline Urea $\left(\mathrm{mmol} \cdot \mathrm{L}^{-1}\right)$ & $<0.0001$ & 1.05 & 1.05 & 1.06 & 128.9 \\
\hline Haemoglobin $\left(\mathrm{g} \cdot \mathrm{dL}^{-1}\right)$ & $<0.001$ & 0.84 & 0.81 & 0.87 & 96.9 \\
\hline NYHA class & $<0.0001$ & 1.64 & 1.48 & 1.82 & 89.0 \\
\hline Creatinine $\left(\mathrm{u} \cdot \mathrm{moL}^{-1}\right)^{*}$ & $<0.001$ & 1.023 & 1.016 & 1.029 & 58.3 \\
\hline Diastolic BP (mmHg) & $<0.001$ & 0.99 & 0.98 & 0.99 & 42.4 \\
\hline Sodium $\left(\mathrm{mmol} \cdot \mathrm{L}^{-1}\right)$ & $<0.001$ & 0.96 & 0.94 & 0.97 & 27.1 \\
\hline QRS duration $(\mathrm{ms})^{*}$ & $<0.001$ & 1.05 & 1.03 & 1.07 & 18.3 \\
\hline $\operatorname{BMI}\left(\mathrm{kg} \cdot \mathrm{m}^{-2}\right)$ & $<0.001$ & 0.98 & 0.97 & 0.99 & 14.6 \\
\hline Systolic BP (mmHg) & $<0.001$ & 1.00 & 0.99 & 1.00 & 8.9 \\
\hline Heart rate (beats. $\min ^{-1}$ ) & 0.01 & 1.00 & 1.00 & 1.01 & 7.1 \\
\hline
\end{tabular}

HR: hazard ratio; 95\% CI: 95\% confidence intervals; 6-MWT: 6-minute walk test; NYHA: New York Heart Association; LVI: left ventricular impairment; ${ }^{*}$ HR reported for 10-unit increment.

TABLE 4: Bootstrap model based on 1000 stratified samples. Univariable predictors listed in order of magnitude of $P$ value.

\begin{tabular}{|c|c|c|c|c|c|c|}
\hline \multirow{3}{*}{ Variables } & \multirow{3}{*}{$B$} & \multicolumn{5}{|c|}{ Bootstrap } \\
\hline & & \multirow{2}{*}{ Bias } & \multirow{2}{*}{ SE } & \multirow{2}{*}{$P$ value } & \multicolumn{2}{|c|}{$95 \% \mathrm{CI}$} \\
\hline & & & & & Lower & Upper \\
\hline Log NT pro-BNP & 0.489 & -0.001 & 0.35 & 0.001 & 0.418 & 0.556 \\
\hline 6-MWT (m) & -0.002 & 0.0001 & 0.0001 & 0.001 & -0.002 & -0.001 \\
\hline Age (years) & 0.042 & -0.001 & 0.004 & 0.001 & 0.033 & 0.050 \\
\hline NYHA class & 0.136 & 0.004 & 0.060 & 0.023 & 0.027 & 0.263 \\
\hline Diastolic BP (mmHg) & -0.007 & 0.0001 & 0.003 & 0.030 & -0.013 & -0.001 \\
\hline Haemoglobin $\left(\mathrm{g} \cdot \mathrm{dL}^{-1}\right)$ & -0.041 & -0.002 & 0.021 & 0.049 & -0.082 & 0.002 \\
\hline Urea $\left(\mathrm{mmol} \cdot \mathrm{L}^{-1}\right)$ & 0.024 & -0.002 & 0.014 & 0.068 & -0.006 & 0.047 \\
\hline Sodium $\left(\mathrm{mmol} \cdot \mathrm{L}^{-1}\right)$ & -0.014 & -0.001 & 0.010 & 0.182 & -0.034 & 0.007 \\
\hline QRS duration $\left(\mathrm{m} \cdot \mathrm{s}^{-1}\right)$ & 0.001 & 0.0001 & 0.001 & 0.253 & -0.001 & 0.004 \\
\hline Systolic BP (mmHg) & 0.001 & 0.0001 & 0.002 & 0.528 & -0.002 & 0.005 \\
\hline Creatinine $\left(\mathrm{u} \cdot \mathrm{moL}^{-1}\right)$ & 0.001 & 0.0001 & 0.001 & 0.667 & -0.001 & 0.004 \\
\hline Heart rate (beats. $\mathrm{min}^{-1}$ ) & 0.000 & 0.0001 & 0.002 & 0.736 & -0.002 & 0.005 \\
\hline Potassium $\left(\mathrm{mmol} \cdot \mathrm{L}^{-1}\right)$ & -0.001 & 0.0001 & 0.073 & 0.982 & -0.143 & 0.137 \\
\hline
\end{tabular}

SE: standard error; 95\% CI: 95\% confidence intervals; 6-MWT: 6-minute walk test; NYHA: New York Heart Association; LVI: left ventricular impairment.

TABLE 5: Multivariable predictors of long-term all-cause mortality in patients with CHF: final model (listed in order of magnitude of Wald statistic).

\begin{tabular}{|c|c|c|c|c|c|}
\hline \multirow{2}{*}{ Variables } & \multirow{2}{*}{$P$ value } & \multirow{2}{*}{ Wald } & \multirow{2}{*}{$\mathrm{HR}$} & \multicolumn{2}{|c|}{$95 \% \mathrm{CI}$} \\
\hline & & & & Lower & Upper \\
\hline Log NT pro-BNP & $<0.0001$ & 86.3 & 1.393 & 1.299 & 1.494 \\
\hline 6-MWT $(\mathrm{m})^{*}$ & $<0.0001$ & 57.2 & 0.980 & 0.974 & 0.985 \\
\hline Age (years) & $<0.0001$ & 29.9 & 1.026 & 1.017 & 1.036 \\
\hline Diastolic BP (mmHg) & 0.001 & 12.8 & 0.990 & 0.984 & 0.995 \\
\hline Urea $\left(\mathrm{mmol} \cdot \mathrm{L}^{-1}\right)$ & 0.002 & 9.5 & 0.980 & 0.974 & 0.985 \\
\hline Sodium $\left(\mathrm{mmol} \cdot \mathrm{L}^{-1}\right)$ & 0.052 & 3.8 & 0.978 & 0.957 & 1.000 \\
\hline
\end{tabular}

HR: hazard ratio; 95\% CI: 95\% confidence intervals; 6-MWT: 6-minute walk test; NYHA: New York Heart Association; ${ }^{*}$ HR reported for 10-unit increment. 


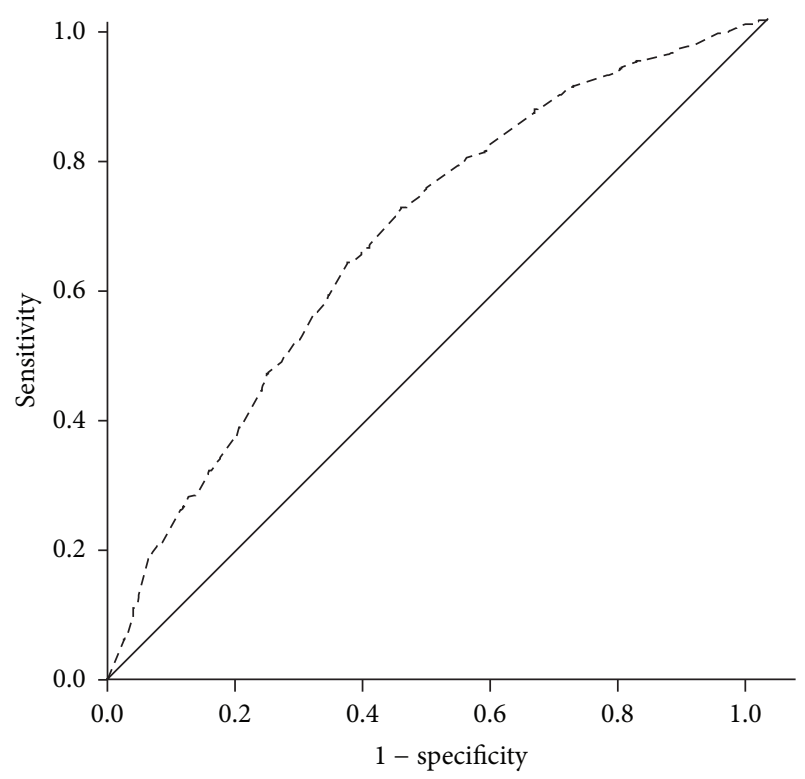

FIGURE 1: Receiver operating characteristic curve showing value of the 6-MWT for predicting all-cause mortality at 5 years in patients with $\mathrm{CHF}(\mathrm{AUC}=0.67 ; P<0.0001 ; 95 \% \mathrm{CI}=0.64-0.70$; sensitivity $=0.81$; specificity $=0.57$; optimal cut-point $=350 \mathrm{~m}$ ).

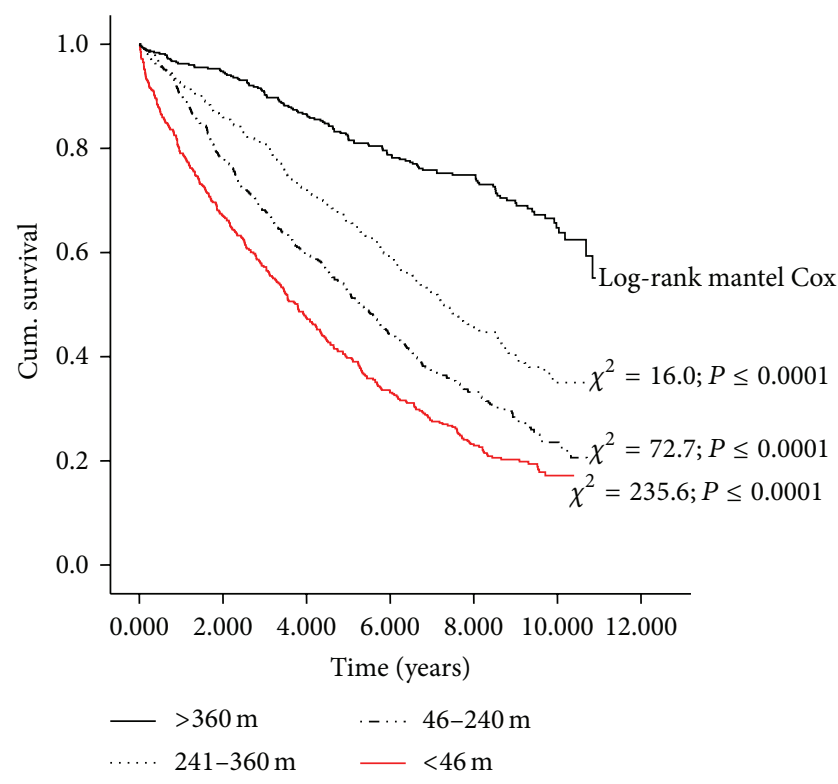

FIGURE 2: Kaplan-Meier survival curve showing quartiles of 6MWT distance $(\mathrm{m})(<46 \mathrm{~m}$, event free survival $24 \% ; 46-240 \mathrm{~m}$, event free survival 29\%; 241-360 m, event free survival $45 \%$; $>360 \mathrm{~m}$, event free survival 70\%).

concluded that 6-MWT distance (mean followup $387 \pm 177$ days) does not provide complimentary prognostic information or should be substituted for peak oxygen consumption. In a study of only 253 patients with either systolic or diastolic heart failure in whom there were 43 cardiac events over 4 years, Guazzi et al. [11] found that although 6-MWT distance correlated with peak oxygen uptake and $\mathrm{VE} / \mathrm{VCO}_{2}$ slope, there was no significant association between 6-MWT distance and survival. However, CPET-derived variables were predictors of prognosis.

Most studies using CPET variables as potential predictors of outcome have followed up patients for two years or less. Studies have reported very short-term (e.g., 6 months or less) followup [26, 27], 12 months [28-31] or up to 2 years [26, 3237]. Few studies have reported tracking periods beyond 3 years $[38,39]$. Prognostic models for patients with heart failure usually contain variables from domains measuring some aspect of exercise capacity, some indicator of cardiac function (such as left ventricular ejection fraction), and some indicator of systemic involvement (such as creatinine). CPET is not widely available. We show here that the simple and cheap 6-MWT distance is an easily obtainable variable which strongly relates to long-term survival in patients with CHF.

4.1. Study Limitations. The 6-MWT is not a test of maximal exercise capacity but is a test of submaximal exercise performance [6]. The American Thoracic Society [7] advocates that verbal encouragement should be limited and tone of voice be controlled during the 6-MWT in an elderly, chronic disease population. We have followed this approach with our patients but different centres will operate different systems. Therefore, findings from our current study should not be extrapolated to other populations or to other research centres that may use a more aggressive 6-MWT coaching style.

4.2. Conclusion. The 6-MWT is an independent predictor of all-cause mortality following long-term (5-year) followup in patients with CHF. It provides similar or better discriminatory power than other routinely collected physical and biochemical variables and, as such, might make a reasonable target for treatment.

\section{Conflict of Interests}

The authors declare that there is no conflict of interests regarding the publication of this paper.

\section{References}

[1] C. Schalcher, H. Rickli, M. Brehm et al., "Prolonged oxygen uptake kinetics during low-intensity exercise are related to poor prognosis in patients with mild-to-moderate congestive heart failure," Chest, vol. 124, no. 2, pp. 580-586, 2003.

[2] M. Guazzi, V. Adams, V. Conraads et al., "EACPR/AHA scientific statement. Clinical recommendations for cardiopulmonary exercise testing data assessment in specific patient populations," Circulation, vol. 126, no. 18, pp. 2261-2274, 2012.

[3] L. Ingle, R. J. Shelton, A. S. Rigby, S. Nabb, A. L. Clark, and J. G. F. Cleland, "The reproducibility and sensitivity of the 6min walk test in elderly patients with chronic heart failure," European Heart Journal, vol. 26, no. 17, pp. 1742-1751, 2005.

[4] D. P. Lipkin, A. J. Scriven, T. Crake, and P. A. Poole-Wilson, "Six minute walking test for assessing exercise capacity in chronic heart failure," British Medical Journal, vol. 292, no. 6521, pp. 653$655,1986$. 
[5] L. G. Olsson, K. Swedberg, A. L. Clark, K. K. Witte, and J. G. F. Cleland, "Six minute corridor walk test as an outcome measure for the assessment of treatment in randomized, blinded intervention trials of chronic heart failure: a systematic review," European Heart Journal, vol. 26, no. 8, pp. 778-793, 2005.

[6] L. Ingle, M. Wilkinson, S. Carroll et al., "Cardiorespiratory requirements of the 6-min walk test in older patients with left ventricular systolic dysfunction and no major structural heart disease," International Journal of Sports Medicine, vol. 28, no. 8, pp. 678-684, 2007.

[7] R. O. Crapo, R. Casaburi, A. L. Coates et al., "ATS statement: guidelines for the six-minute walk test," American Journal of Respiratory and Critical Care Medicine, vol. 166, no. 1, pp. 111117, 2002.

[8] V. Bittner, D. H. Weiner, S. Yusuf et al., "Prediction of mortality and morbidity with a 6-minute walk test in patients with left ventricular dysfunction," Journal of the American Medical Association, vol. 270, no. 14, pp. 1702-1707, 1993.

[9] L. Ingle, K. Goode, A. S. R. Rigby, J. G. F. Cleland, and A. L. Clark, "Predicting peak oxygen uptake from 6-min walk test performance in male patients with left ventricular systolic dysfunction," European Journal of Heart Failure, vol. 8, no. 2, pp. 198-202, 2006.

[10] L. Ingle, A. S. Rigby, S. Carroll et al., "Prognostic value of the 6 min walk test and self-perceived symptom severity in older patients with chronic heart failure," European Heart Journal, vol. 28, no. 5, pp. 560-568, 2007.

[11] M. Guazzi, K. Dickstein, M. Vicenzi, and R. Arena, "Six-minute walk test and cardiopulmonary exercise testing in patients with chronic heart failure: a comparative analysis on clinical and prognostic insights," Circulation: Heart Failure, vol. 2, no. 6, pp. 549-555, 2009.

[12] National Institute for Clinical Excellence (NICE), Chronic Heart Failure: Management of Chronic Heart Failure in Adults in Primary and Secondary Care, vol. 5 of Clinical Guidelines, NICE, London, UK, 2003.

[13] W. J. Remme and K. Swedberg, "Comprehensive guidelines for the diagnosis and treatment of chronic heart failure: task force for the diagnosis and treatment of chronic heart failure of the European Society of Cardiology," European Journal of Heart Failure, vol. 4, no. 1, pp. 11-22, 2002.

[14] N. B. Schiller, P. M. Shah, M. Crawford et al., "Recommendations for quantitation of the left ventricle by twodimensional echocardiography. American Society of Echocardiography Committee on Standards, Subcommittee on Quantitation of Two-Dimensional Echocardiograms," Journal of the American Society of Echocardiography, vol. 2, no. 5, pp. 358-367, 1989.

[15] V. Bittner, D. H. Weiner, S. Yusuf et al., "Prediction of mortality and morbidity with a 6-minute walk test in patients with left ventricular dysfunction," Journal of the American Medical Association, vol. 270, no. 14, pp. 1702-1707, 1993.

[16] S. J. Pocock, T. C. Clayton, and D. G. Altman, "Survival plots of time-to-event outcomes in clinical trials: good practice and pitfalls," The Lancet, vol. 359, no. 9318, pp. 1686-1689, 2002.

[17] P. M. Grambsch and T. M. Therneau, "Proportional hazards tests and diagnostics based on weighted residuals," Biometrika, vol. 81, no. 3, pp. 515-526, 1994.

[18] E. W. Steyerberg, M. J. C. Eijkemans, F. E. Harrell Jr., and J. D. F. Habbema, "Prognostic modeling with logistic regression analysis: in search of a sensible strategy in small data sets," Medical Decision Making, vol. 21, no. 1, pp. 45-56, 2001.
[19] P. Peduzzi, J. Concato, A. R. Feinstein, and T. R. Holford, "Importance of events per independent variable in proportional hazards regression analysis II. Accuracy and precision of regression estimates," Journal of Clinical Epidemiology, vol. 48, no. 12, pp. 1503-1510, 1995.

[20] T. V. Perneger, "What's wrong with Bonferroni adjustments?" British Medical Journal, vol. 316, no. 7139, pp. 1236-1238, 1998.

[21] L. Manzano, D. Babalis, M. Roughton et al., "Predictors of clinical outcomes in elderly patients with heart failure," European Journal of Heart Failure, vol. 13, no. 5, pp. 528-536, 2011.

[22] C. Rostagno, G. Olivo, M. Comeglio et al., "Prognostic value of 6-minute walk corridor test in patients with mild to moderate heart failure: comparison with other methods of functional evaluation," European Journal of Heart Failure, vol. 5, no. 3, pp. 247-252, 2003.

[23] A. L. Beatty, N. B. Schiller, and M. A. Whooley, "Six-minute walk test as a prognostic tool in stable coronary heart disease: data from the heart and soul study," Archives of Internal Medicine, vol. 172, no. 14, pp. 1096-1102, 2012.

[24] C. Lucas, L. W. Stevenson, W. Johnson et al., "The 6-min walk and peak oxygen consumption in advanced heart failure: aerobic capacity and survival," American Heart Journal, vol. 138, no. 4, pp. 618-624, 1999.

[25] C. Opasich, G. D. Pinna, A. Mazza et al., "Six-minute walking performance in patients with moderate-to-severe heart failure: is it a useful indicator in clinical practice?" European Heart Journal, vol. 22, no. 6, pp. 488-496, 2001.

[26] A. K. Gitt, K. Wasserman, C. Kilkowski et al., "Exercise anaerobic threshold and ventilatory efficiency identify heart failure patients for high risk of early death," Circulation, vol. 106, no. 24, pp. 3079-3084, 2002.

[27] E. A. Jankowska, T. Witkowski, B. Ponikowska et al., "Excessive ventilation during early phase of exercise: a new predictor of poor long-term outcome in patients with chronic heart failure," European Journal of Heart Failure, vol. 9, no. 10, pp. 1024-1031, 2007.

[28] R. Arena, R. Humphrey, and M. A. Peberdy, "Prognostic ability of $\mathrm{VE} / \mathrm{VCO}_{2}$ slope calculations using different exercise test time intervals in subjects with heart failure," European Journal of Cardiovascular Prevention and Rehabilitation, vol. 10, no. 6, pp. 463-468, 2003.

[29] R. Arena, J. Myers, S. S. Aslam, E. B. Varughese, and M. A. Peberdy, "Influence of subject effort on the prognostic value of peak $\mathrm{VO}_{2}$ and the $\mathrm{VE} / \mathrm{VCO}_{2}$ slope in patients with heart failure," Journal of Cardiopulmonary Rehabilitation, vol. 24, no. 5, pp. 317-320, 2004.

[30] R. Arena, J. Myers, J. Abella et al., "Development of a ventilatory classification system in patients with heart failure," Circulation, vol. 115, no. 18, pp. 2410-2417, 2007.

[31] M. Guazzi, J. Myers, M. A. Peberdy, D. Bensimhon, P. Chase, and R. Arena, "Exercise oscillatory breathing in diastolic heart failure: prevalence and prognostic insights," European Heart Journal, vol. 29, no. 22, pp. 2751-2759, 2008.

[32] A. Cohen-Solal, J. Y. Tabet, D. Logeart, P. Bourgoin, M. Tokmakova, and M. Dahan, "A non-invasively determined surrogate of cardiac power ("circulatory power") at peak exercise is a powerful prognostic factor in chronic heart failure," European Heart Journal, vol. 23, no. 10, pp. 806-814, 2002.

[33] G. A. MacGowan, K. Janosko, A. Cecchetti, and S. Murali, "Exercise-related ventilatory abnormalities and survival in congestive heart failure," The American Journal of Cardiology, vol. 79, no. 9, pp. 1264-1266, 1997. 
[34] C. Scharf, T. Merz, W. Kiowski, E. Oechslin, C. Schalcher, and H. P. Brunner-La Rocca, "Noninvasive assessment of cardiac pumping capacity during exercise predicts prognosis in patients with congestive heart failure," Chest, vol. 122, no. 4, pp. 13331339, 2002.

[35] M. Cicoira, C. H. Davos, D. P. Francis et al., "Prediction of mortality in chronic heart failure from peak oxygen consumption adjusted for either body weight or lean tissue," Journal of Cardiac Failure, vol. 10, no. 5, pp. 421-426, 2004.

[36] T. P. Chua, P. Ponikowski, D. Harrington et al., "Clinical correlates and prognostic significance of the ventilatory response to exercise in chronic heart failure," Journal of the American College of Cardiology, vol. 29, no. 7, pp. 1585-1590, 1997.

[37] D. P. Francis, W. Shamim, L. C. Davies et al., "Cardiopulmonary exercise testing for prognosis in chronic heart failure: continuous and independent prognostic value from $\mathrm{VE} / \mathrm{VCO}_{2}$ slope and peak $\mathrm{VO}_{2}$," European Heart Journal, vol. 21, no. 2, pp. 154$161,2000$.

[38] L. Ingle, K. K. Witte, J. G. J. F. Cleland, and A. L. Clark, “The prognostic value of cardiopulmonary exercise testing with a peak respiratory exchange ratio of $<1.0$ in patients with chronic heart failure," International Journal of Cardiology, vol. 127, no. 1, pp. 88-92, 2008.

[39] L. C. Davies, D. P. Francis, M. Piepoli, A. C. Scott, P. Ponikowski, and A. J. S. Coats, "Chronic heart failure in the elderly: value of cardiopulmonary exercise testing in risk stratification," Heart, vol. 83, no. 2, pp. 147-151, 2000. 


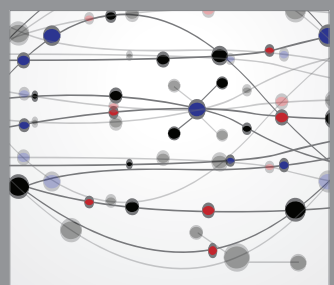

The Scientific World Journal
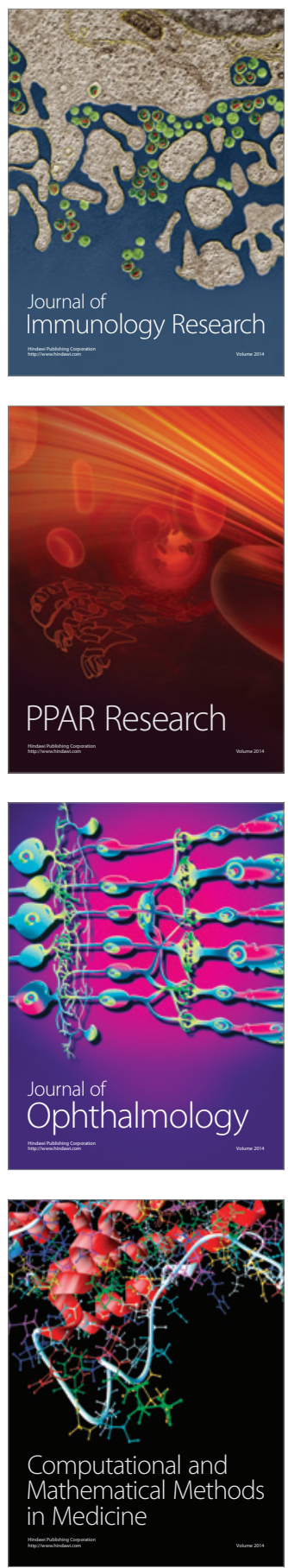

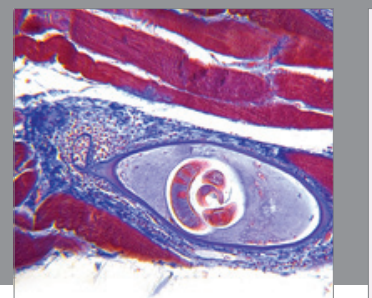

Gastroenterology

Research and Practice
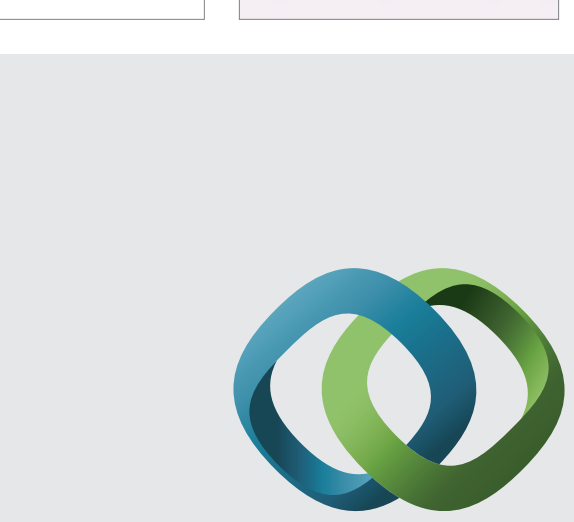

\section{Hindawi}

Submit your manuscripts at

http://www.hindawi.com
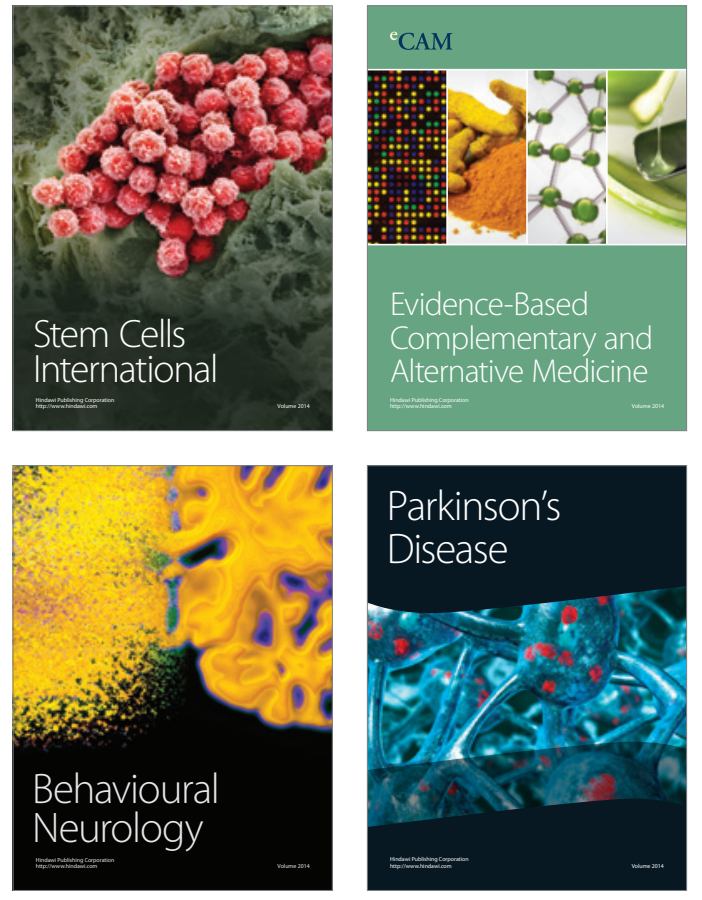
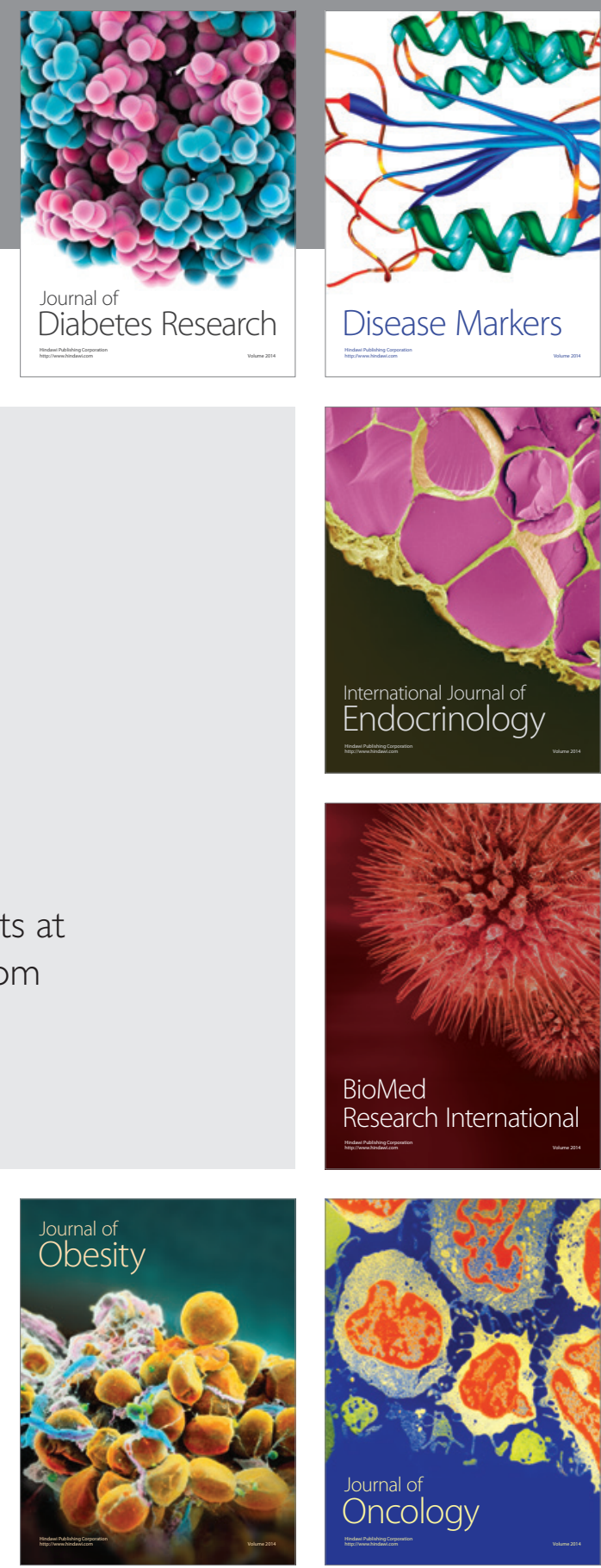

Disease Markers
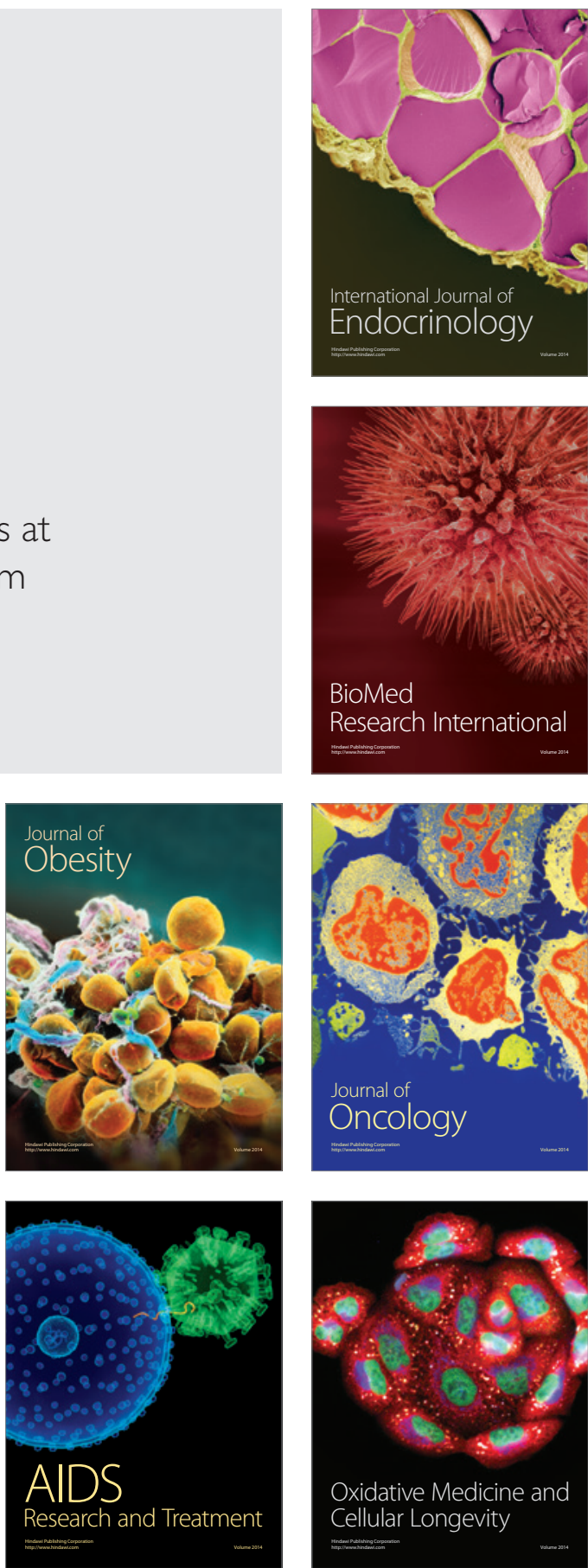